\title{
Article
}

\section{Performance Evaluation of a Two-Parameters Monthly Rainfall-Runoff Model in The Southern Basin of Thailand}

\author{
Pakorn Ditthakit ${ }^{1,3, *}$, Sirimon Pinthong ${ }^{1,3}$, Nureehan Salaeh ${ }^{1,3}$, Fadilah Binnui ${ }^{1,3}$, and Laksanara Khwanchum ${ }^{2,3}$ \\ 1 School of Engineering and Technology, Walailak University, Nakhon Si Thammarat 80161, Thailand; \\ dpakorn@mail.wu.ac.th (P.D.); Sirimon.pi@mail.wu.ac.th (S.P.); Nureehan.sa@mail.wu.ac.th (N.S.); \\ Fadilah.bi@mail.wu.ac.th (F.B.) \\ 2 School of Languages and General Education, Walailak University, Nakhon Si Thammarat 80161, Thailand; \\ laksanara.kh@wu.ac.th (L.K.) \\ 3 Center of Excellence in Sustainable Disaster Management, Walailak University, Nakhon Si Thammarat \\ 80161, Thailand \\ * Correspondence: dpakorn@mail.wu.ac.th (P.D.); Tel.:+66-7567-2321 (P.D.)
}

\begin{abstract}
Accurate monthly runoff estimation is fundamental in water resources management, planning, and development, resulting in preventing and reducing water-related problems, such as flooding and drought. This article evaluates the performance of the monthly hydrological rainfall-runoff model, GR2M model, in Thailand's southern basins. The GR2M model requires only two parameters, and no prior research has been reported on its application in this region. The 37 runoff stations, which are distributively located in three sub-watersheds of Thailand's southern region, namely; Thale Sap Songkhla, Peninsular-East Coast, and Peninsular-West Coast, were selected as study cases. The available monthly hydrological data of runoff, rainfall, air temperature from the Royal Irrigation Department (RID) and the Thai Meteorological Department (TMD) were collected and analyzed. Thornthwaite method was utilized for the determination of evapotranspiration. The model's performance was conducted using three statistical indices: Nash-Sutcliffe Efficiency (NSE), Correlation Coefficient (r), and Overall Index (OPI). The model's calibration results for 37 runoff stations gave the average of NSE, r, and OPI of $0.637,0.825$, and 0.757 , and those values for verification of $0.465,0.750$, and 0.639 , respectively. It indicated a model's acceptable performance and could apply the GR2M model for determining monthly runoff variation in this region. The spatial distribution of X1 and X2 values was conducted by using IDW method. It was susceptible to the X1 value and $\mathrm{X} 2$ value of approximately more than 0.90 gave the higher model's performance.
\end{abstract}

Keywords: GR2M, Inverse Distance Weighting, Rainfall-Runoff Model, Sensitivity Analysis

\section{Introduction}

The southern region of Thailand is an area characterized by a tropical climate since it is close to the equator, and the Northeast and Southwest influence it. Consequently, many areas have been experiencing flooding problems leading to a vast majority of devastation to human beings' lives and properties that hindered economic growth and development. Each year, during a dry spell of approximately two months, this region usually faces a drought situation due to increasing water demand from all activities and insufficient water supply and storage. Accurate estimating runoff quantity and its time variation can help water resources management-related personnel for disaster response planning, preventing and reducing the adverse impact [1]. Hence, it is fundamentally imperative to obtain a hydrological information since water supply is in demand from all activities, including domestic consumption, agriculture, and various industries [2-4].

Although runoff is essential information, most hydrologists cannot access it due to insufficient runoff measuring stations compared to rainfall measuring stations equipped 
throughout the country's regions [5]. Many research topics regarding the rainfall-runoff model have been studied, developed, and applied by hydrologists and irrigation engineers for many aspects. For example, Chen, et al. [6], Kabiri, et al. [7], Lin, et al. [8] applied the rainfall-runoff model to assess runoff impacts due to climate and land-use change. Kwak, et al. [9] also used the rainfall-runoff model to reconstruct the missing runoff time-series information. Similarly, Ballinas-González, et al. [10] studied the sensitivity analysis of the rainfall-runoff modeling parameters in the data-scarce urban catchment. Lerat, et al. [11] proposed the alternative method for calibrating daily rainfall-runoff models to monthly streamflow data when no daily streamflow data recorded. Likewise, Abdessamed and Abderrazak [12] utilized a coupling HEC-RAS and HEC-HMS modeling for evaluating floodplain inundation maps in arid environments. Zhang, et al. [13] tested the performance of the shuffled complex evolution (SCE-UA) as a global optimization method to calibrate the Xinanjiang (XAJ) model. Lastly, Khazaei, et al. [14] applied a simple genetic algorithm (SGA) to automatically calibrate the ARNO conceptual rainfall-runoff model.

The Rural Genius model or GR2M model has recently been successfully applied as a rainfall-runoff relationship model to comprehend the variation of watershed's hydrological characteristics and to determine alleviation measures of unexpected situations in many regions throughout the world. Dezetter, et al. [15] applied the GR2M model for study runoff in West Africa due to climate variability on hydrologic regimes for large-scale water resources management and planning. Okkan and Fistikoglu [16] evaluated the effects of climate change on runoff in the Izmir-Tahtali watershed, Turkey, using statistical downscaling under the AR5 scheme and GR2M model. They recommended that it immediately took on the drought alleviating water supply and agriculture measures on a national scale. Lyon, et al. [17] utilized the GR2M model as the first step for screening hydrologic data for evaluating the changes of hydrological response across the Lower Mekong Basin. Zamoum and Souag-Gamane [18] developed regionalized parameters of the GR2M model for predicting monthly runoff in the ungauged catchment of northern Algeria. Boulariah, et al. [19] conducted a comparative study between two conceptual nonlinear models, i.e., the GR2M and the ABCD. The results showed that the GR2M model outperformed the ABCD in the validation phase. Topalović, et al. [20] compared four monthly rainfall-runoff models based on the water balance concept, i.e., abcd, Budyko, GR2M, and WASMOD to simulate runoff in the Wimmera catchment under changing climate conditions. Hadour, et al. [21] applied the GR2M model to study the effects of climate scenario on monthly river runoff in the Cheliff, Tafna, and Macta in North-West Algeria. Rintis and Setyoasri [22] compared the GR2M model's performance to two well-known rainfall-runoff models in Indonesia, that is, Mock and NRECA. Using the Bah Bolon Basin in Indonesia as a studied area, they found the GR2M model's performance was comparable to Mock and NRECA methods requiring fewer parameters. O. Connor, et al. [23] applied the GR2M hydrological model and an Artificial Neural Network for reconstructing monthly river flow for Irish catchments.

The spatiotemporal characteristic with a hydrological analysis of Southern Basins of Thailand constitutes a vital platform for understanding the hydrological behavior. It gives particular interest to the valorization of the hydraulic potential. Hydrological modeling is essential for studying the development and management of water resources in the watershed. The main reason for choosing GR2M in this study is that it requires few hydrological information ( rainfall data, potential evapotranspiration, and flow rates), and only two model's parameters can be calibrated. This article mainly focused on investigating the monthly hydrological rainfall-runoff model, GR2M model, in Thailand's southern basins, namely, Songkhla Lake Basin, West basin, and the Eastern Basin. The study's novelty is that it is the first attempt to apply a two-parameters monthly rainfall-runoff model, the GR2M model, in Thailand's southern basins. It is also dras- 
tically useful for water resources planning and management in this region. This article is organized in the following ways: section 1 reviews the study area's dominant characteristic and data analysis for model input. In section 2, the GR2M theory is briefly examined. The model's calibration and verification are delineated in section 3 . The performance criteria for evaluating the applicability of the GR2M Model is depicted in section 4 . Our result findings and discussion are portrayed in section 5. Finally, in section 6, we concluded significant contributions from our research work.

\section{Study Area and Data Analysis}

This research was conducted in Thailand's southern basin. It encompasses five major river basins, including the Peninsula-East Coast. Peninsula-West Coast, Mae Nam Tapi, Thale Sap Songkhla, and Mae Nam Pattani, as shown in Figure 1. When investigating monthly rainfall, evapotranspiration, and runoff data, we found only three river basins, i.e. the Peninsula-East Coast, Peninsula-West Coast, Thale Sap Songkhla. Thus, we focused our experiment in these three basins. These river basins have an area of approximately in the range of 13 to $6,713 \mathrm{~km}^{2}$. Geographically, this portion is the peninsula between the Andaman Sea, which is on the western side, and the South China Sea, which is on the eastern side. The long western mountain range in the northern and central regions also extends to this portion. The Phuket ridge along the west coast and the Nakhon Si Thammarat ridge at the center of the lower portion of the ridge's southern part is divided into two regions: the east and the west coasts. Climate variability on both sides of the river basins is mainly dominated by the north-eastern monsoon and the south-western monsoon winds. The southwest monsoon wind typically starts in mid-May and ends in mid-October, while the northeast monsoon typically begins in mid-October and ends in mid-February.

The Peninsula-East Coast watershed covers an area of $26023.91 \mathrm{~km}^{2}$ and encompasses 11 provinces. It also consists of areas covering all parts of the provinces of Chumphon, Trang, Nakhon Si Thammarat, Narathiwat, Prachuap Khiri Khan, Pattani, Phatthalung, Yala, Ranong, Songkhla, and Surat Thani. The flat coast has a small plain from Chumphon to Narathiwat. Additionally, most rivers are short rivers with a length not more than approximately $150 \mathrm{~km}$ flowing into the Gulf of Thailand. There are nine runoff stations in the Peninsula-East Coast watershed. The Peninsula-West Coast Watershed, $18841.20 \mathrm{~km}^{2}$, consists of seven provinces: Ranong, Phang Nga, Phuket, Krabi, Nakhon Si Thammarat, Trang, and Satun. It also includes Chumphon, Surat Thani, Phatthalung, and Songkhla, with similar topography to the Peninsula-East Coast Watershed. It is a coastal area next to the Andaman Sea. The Phuket Mountains go from Ranong Province to Phang Nga Province, the origin of various rivers and streams. They are generally not long, and they flow mainly to the Andaman Sea in the west and southwest directions. The nineteen runoff stations were used for our analysis. Thale Sap Songkhla watershed, an area of $8484.35 \mathrm{~km}^{2}$, primarily covers three provinces, the province of Nakhon Si Thammarat (Some portions of the district of Cha-Uat and the district of Hua Sai), the province of Phatthalung, both provinces, and the province of Songkhla, except for the district of Nathawi, the district of Chana, the district of Thepha and the district of Saba Yoi). Thus, 147 sub-districts and 26 districts, with nine runoff stations, were the setting of our study. Figure 1 shows the location of rainfall, runoff, and weather stations selected in Thailand's southern basin. 


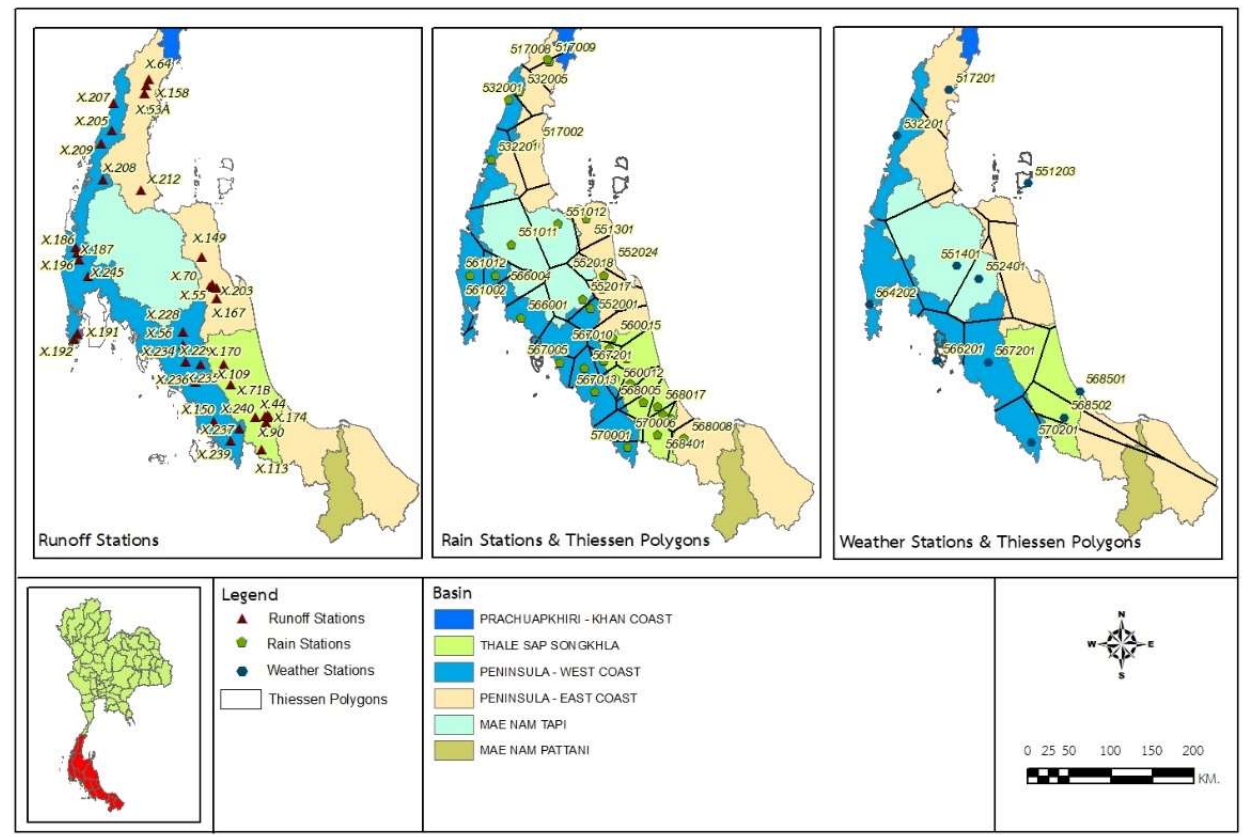

Figure 1. Location of rainfall, runoff, and weather stations selected in the southern basin of Thailand.

We collected the monthly meteorological and hydrological data from the Royal Irrigation Department (RID) and the Thai Meteorological Department (TMD), including runoff ( 37 stations), rainfall ( 38 stations), and air temperature (13 stations) as shown in the statistical values in Figure 2. We also investigated and analyzed the time corresponding among those three meteorological and hydrological data to select the suitable periods of model's calibration and verification, as shown in Table 1. The thiessen polygon was used to determine the mean areal precipitation in the considered basin from rain gauge observations. The monthly evapotranspiration, which is one of the input data for the GR2M model, was calculated from the average monthly air temperature ( Ti) data by Thornthwaite [24], as shown below:

- Monthly values of heat index

$$
\mathrm{I}_{\mathrm{i}}=\left(\frac{\mathrm{T}_{\mathrm{i}}}{5}\right)^{1.514}
$$

- Annual temperature efficiency index

$$
\mathrm{J}=\sum_{\mathrm{i}=1}^{12}\left(\mathrm{I}_{\mathrm{i}}\right)
$$

- Evapotranspiration

$$
\operatorname{PET}_{\mathrm{i}}(0)=1.6\left(\frac{10 \mathrm{~T}_{\mathrm{i}}{ }^{\mathrm{C}}}{\mathrm{J}}\right)^{\mathrm{C}}
$$

- The $\mathrm{C}$ value can be obtained from:

$$
\mathrm{C}=0.000000675 \mathrm{~J}^{3}-0.0000771 \mathrm{~J}^{2}+0.01792 \mathrm{~J}+0.49239
$$

- Potential Evapotranspiration

$$
\operatorname{PET}_{\mathrm{i}}(\mathrm{L})=\mathrm{K} \times \operatorname{PET}_{\mathrm{i}}(0)
$$

Where $: T_{i}=$ Monthly average temperature $\left(C^{\circ}\right)$

$\mathrm{K}=$ PET constants at different latitudes 


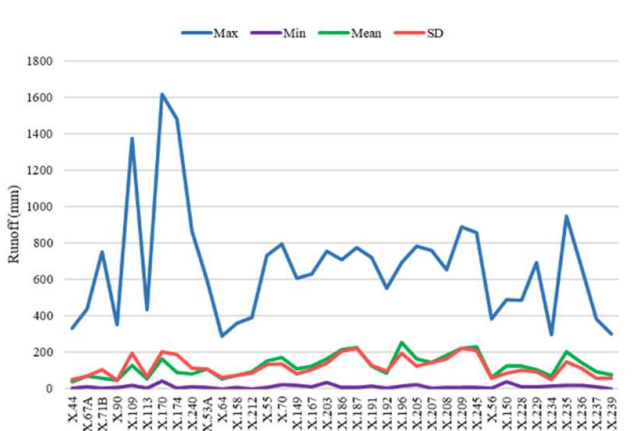

(a)

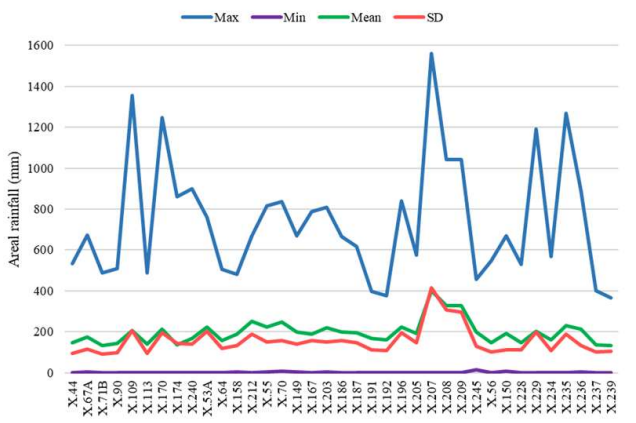

(b)

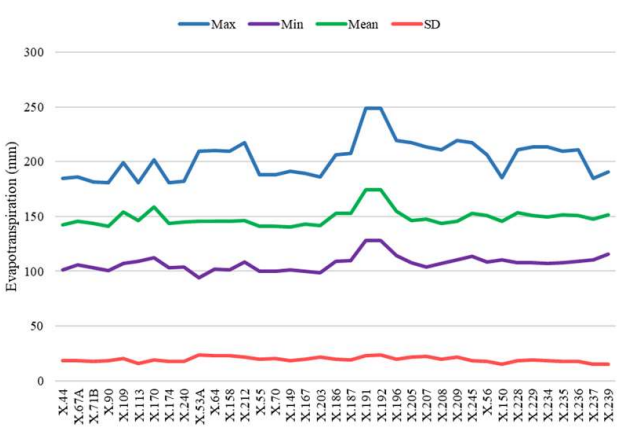

(C)

Figure 2. Statistical values of monthly (a) runoff, (b) rainfall and (c) evapotranspiration data used in this analysis

\section{GR2M Model}

The GR2M, a conceptual model, was first introduced by Demagref in the late 1980s to use water resources management. The model's purpose is to simulate the relationship between monthly rainfall and runoff and reproduce the hydrological system's response. It has been continuously being developed to improve its efficiency by Kabouya 1990 [25], Makhlouf and Michel 1994 [26], Mouelhi 2003 [27] until Mouelhi 2006 [28]. The model selected in this study was the latest model GR2M 2006. It is the most popular and efficient compared to other models [5]. The GR2M model's advantage is that it requires only two parameters: the ability to retain soil moisture $(X 1)$ and the exchange coefficient water $(X 2)$. Additionally, it needs only three monthly meteorological and hydrological data, i.e., rainfall, runoff, and evapotranspiration $[28,29]$. The GR2M model results give runoff hydrograph as well as other elements such as soil moisture content, surface runoff, the groundwater flow, etc.

The structure of the GR2M model consisted of two reservoirs, as presented in Figure 3. The first reservoir represents soil moisture $(\mathrm{S})$ of the basin controlled by production store or the ability to retain soil moisture: $\mathrm{X} 1(\mathrm{~mm})$. Furthermore, the second reservoir is water flow through the river $(\mathrm{R})$, its capacity is up to $60 \mathrm{~mm}$, and regulated by the exchange coefficient water: $\mathrm{X} 2$. This model starts with the precipitation infiltrated into the soil, causes soil moisture at the level: $\mathrm{S} 1(\mathrm{~mm})$. When the soil reaches a saturation point, the remnants of infiltration rain become rainfall excess: $\mathrm{P} 1(\mathrm{~mm})$. The soil moisture loss from evapotranspiration: E until the remaining moisture level: S2 (mm). Additionally, some moisture content is released as surface water: $\mathrm{P} 2(\mathrm{~mm})$ and gradually released with rainfall excess. This water section is called surface runoff or net rainfall: P3 $(\mathrm{mm})$, which moved into the flow path combined with the remaining water from the previous month: $\mathrm{R}(\mathrm{mm})$. It causes the water content at level $\mathrm{R} 1(\mathrm{~mm})$, where the water volume movement may change because some water may be lost, causing the residual water volume at level: $\mathrm{R} 2$ (mm). Ultimately, the total amount of water discharge into the runoff streamflow gauging station conducted the assessment. 

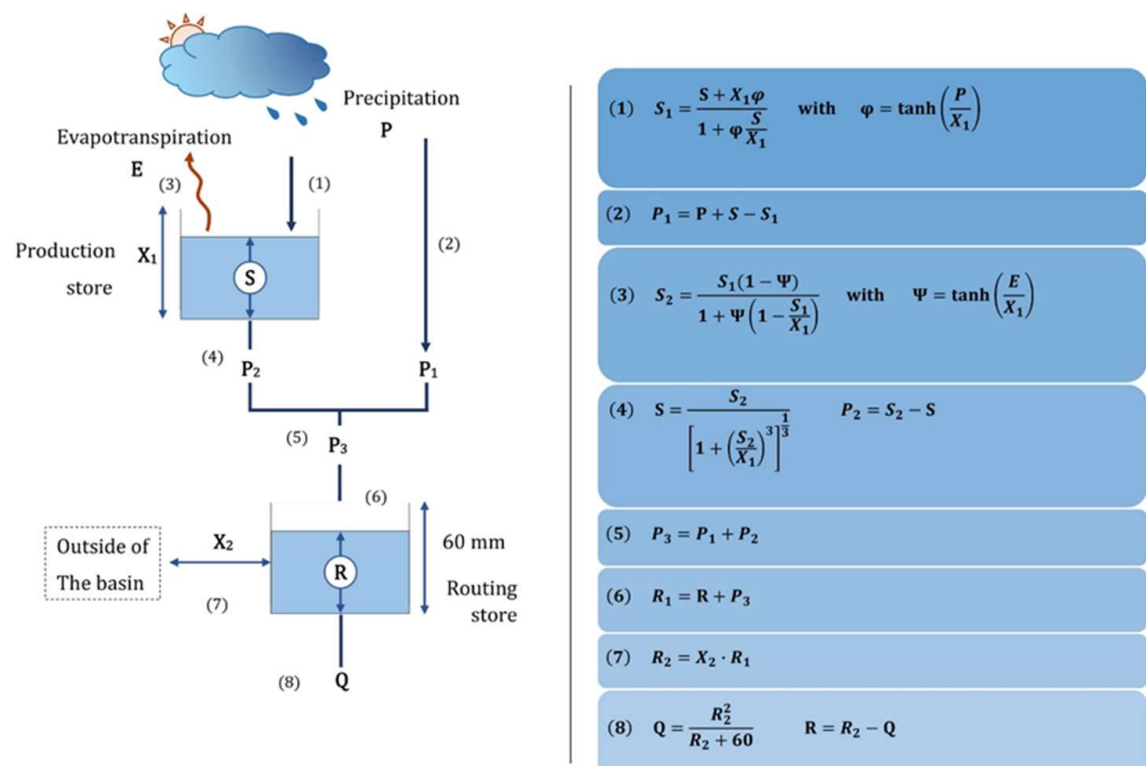

Figure 3. Structure of the GR2M model.

Source: Adapted from Bachir, et al. [30] ; Rwasoka, et al. [31]

\section{Model's calibration and verification}

In achieving our aims in evaluating a Two-Parameters Monthly Rainfall-Runoff Model's performance, the GR2M model, which is applied in the southern basin of Thailand, was calibrated and verified. It included two steps, i.e., the warm-up period and calibrating and verifying the GR2M Model.

\subsection{Warm-up period:}

In this process, the appropriate initial parameters of $\mathrm{X} 1$ and $\mathrm{X} 2$ are determined. It enables the model to mimic the basin's existing hydrological behavior at the considered runoff stations before conducting the model's calibration and verification. The R0 value is varied between $10 \mathrm{~mm}$ and $60 \mathrm{~mm}$ to determine the suitable warm-up period. In our study, we found the warm-up periods of approximately 4 to 7 months.

\subsection{Calibrating and verifying the GR2M Model}

As widely known, the calibration and verification processes are imperative for applying the mathematical model to find the most suitable model's parameters. The model can simulate the behavior of our concerning water system. For the GR2M model, only two parameters: the production store $(\mathrm{X} 1)$ and the exchange coefficient water (X2), must be calibrated and validated. With Microsoft Excel Solver's, it helps by giving an objective function and practical constraints, which can automatically solve the fair values of X1 and X2 parameters for each runoff station. In this study, the GR2M model was calibrated and verified for 37 different runoff stations in the Southern Basins. The details of the intervals for the calibration and verification of the model are presented in Table 1 . It shows that the lowest and the highest periods used for running the GR2M model are 41 and 80 months. It can also more explain the used range regarding the range of calibration and verification periods of 22 and 48 , and 10 and 39 months, respectively.

Table 1. The periods of data used for the GR2M model's calibration and verification.

\begin{tabular}{|c|c|c|c|c|c|c|c|c|c|c|c|}
\hline \multirow{2}{*}{ No. } & \multirow{2}{*}{ de } & \multirow{2}{*}{$\begin{array}{l}\text { Basin } \\
\text { Name }\end{array}$} & \multicolumn{3}{|c|}{ Period (months) } & \multirow{2}{*}{ No. } & \multirow{2}{*}{ Code } & \multirow{2}{*}{$\begin{array}{l}\text { Basin } \\
\text { Name }\end{array}$} & \multicolumn{3}{|c|}{ Period (months) } \\
\hline & & & All & Calibrate & Validate & & & & All & Calibrate & Validate \\
\hline
\end{tabular}




\begin{tabular}{cccccc|cccccc}
\hline 1 & X.44 & TSS & 54 & 29 & 25 & 20 & X.187 & PWC & 67 & 36 & 31 \\
2 & X.67A & TSS & 41 & 23 & 18 & 21 & X.191 & PWC & 67 & 45 & 22 \\
3 & X.71B & TSS & 53 & 30 & 23 & 22 & X.192 & PWC & 66 & 35 & 31 \\
4 & X.90 & TSS & 65 & 45 & 20 & 23 & X.196 & PWC & 67 & 36 & 31 \\
5 & X.109 & TSS & 53 & 38 & 15 & 24 & X.205 & PWC & 79 & 45 & 34 \\
6 & X.113 & TSS & 65 & 37 & 28 & 25 & X.207 & PWC & 79 & 49 & 30 \\
7 & X.170 & TSS & 65 & 40 & 25 & 26 & X.208 & PWC & 44 & 26 & 18 \\
8 & X.174 & TSS & 65 & 39 & 26 & 27 & X.209 & PWC & 68 & 46 & 22 \\
9 & X.240 & TSS & 53 & 27 & 26 & 28 & X.245 & PWC & 44 & 23 & 21 \\
10 & X.53A & PEC & 80 & 41 & 39 & 29 & X.56 & PWC & 55 & 36 & 19 \\
11 & X.64 & PEC & 54 & 36 & 18 & 30 & X.150 & PWC & 42 & 22 & 20 \\
12 & X.158 & PEC & 55 & 37 & 18 & 31 & X.228 & PWC & 65 & 35 & 30 \\
13 & X.212 & PEC & 80 & 47 & 33 & 32 & X.229 & PWC & 65 & 41 & 24 \\
14 & X.55 & PEC & 41 & 25 & 16 & 33 & X.234 & PWC & 54 & 35 & 19 \\
15 & X.70 & PEC & 42 & 32 & 10 & 34 & X.235 & PWC & 54 & 36 & 18 \\
16 & X.149 & PEC & 41 & 30 & 11 & 35 & X.236 & PWC & 56 & 29 & 27 \\
17 & X.167 & PEC & 65 & 36 & 29 & 36 & X.237 & PWC & 55 & 29 & 26 \\
18 & X.203 & PEC & 41 & 26 & 15 & 37 & X.239 & PWC & 55 & 28 & 27 \\
19 & X.186 & PWC & 66 & 39 & 27 & & & & & & \\
\hline \multicolumn{7}{l}{ Remark: TSS =Thale Sap Songkhla; PWC = Peninsular-West Coast; PEC = Peninsular-East Coast. }
\end{tabular}

\section{Performance Criteria for evaluating the applicability of the GR2M Model}

In this study, three performance criteria were used for evaluating the applicability of the GR2M Model. They included Nash-Sutcliffe Efficiency (NSE), Correlation Coefficient (r), and Overall Performance Index (OPI). The details for each performance criteria can be delineated as shown the following:

- Nash-Sutcliffe Efficiency (NSE) is a popular index used to tell model accuracy or efficiency-effectiveness of the model (Model Performance) in estimating the desired value. As the equation below:

$$
\mathrm{NSE}=1-\frac{\sum_{\mathrm{i}=1}^{\mathrm{n}}\left(\mathrm{Q}_{\mathrm{cal}}-\mathrm{Q}_{\mathrm{obs}}\right)^{2}}{\sum_{\mathrm{i}=1}^{\mathrm{n}}\left(\mathrm{Q}_{\mathrm{obs}}-\overline{\mathrm{Q}}_{\mathrm{obs}}\right)^{2}}
$$

NSE is between $-\propto$ to 1 . If the Nash values are close to 1 , then the model results and the measurement results are similar. Which is considered the model of efficiency or accuracy in forecasting [32].

- Correlation Coefficient (r) is a simple linear regression equation. It is a simple linear regression equation can be used to estimate the $\mathrm{Y}$ as well. If $\mathrm{X}$ and $\mathrm{Y}$ are correlated well. The correlation coefficient between $\mathrm{X}$ and $\mathrm{Y}$ can be calculated from the following equation.

$$
\mathrm{r}=\frac{\sum_{\mathrm{i}=1}^{\mathrm{n}}\left(\mathrm{Q}_{\text {obs }}-\overline{\mathrm{Q}}_{\mathrm{obs}}\right)\left(\mathrm{Q}_{\mathrm{cal}}-\overline{\mathrm{Q}}_{\mathrm{cal}}\right)}{\sqrt{\sum_{\mathrm{i}=1}^{\mathrm{n}}\left(\mathrm{Q}_{\mathrm{obs}}-\overline{\mathrm{Q}}_{\mathrm{obs}}\right)^{2}} \cdot \sqrt{\sum_{\mathrm{i}=1}^{\mathrm{n}}\left(\mathrm{Q}_{\text {cal }}-\overline{\mathrm{Q}}_{\text {cal }}\right)^{2}}}
$$

The $r$-value is between -1 and 1 . The squares of $r$ or $R^{2}$ will always be between $0-1$ and in this sense, if $R^{2}$ is 0 , then the two variables have no linear correlation. If $R^{2}$ is equal to 1 , then there is a completely linear correlation. If the $r$ value approaches 1 , the model results and the measurement results are related. In addition, the plus sign (+) or minus sign can also tell the direction of the relationship of the data set. The plus sign (+) means the 
dataset is related. If the data obtained from the model is very valuable. The data obtained from the measurement is also very valuable. The minus sign (-) means the dataset is in the opposite relationship. If the information is valuable More information will be less [33].

- $\quad$ Overall Performance Index (OPI)

$$
\mathrm{OPI}=\frac{1}{2}\left[2-\frac{\mathrm{RMSE}}{\mathrm{Q}_{\mathrm{obs}, \max }-\mathrm{Q}_{\mathrm{obs}, \min }}-\frac{\sum_{\mathrm{i}=1}^{\mathrm{n}}\left(\mathrm{Q}_{\mathrm{obs}}-\mathrm{Q}_{\mathrm{cal}}\right)^{2}}{\sum_{\mathrm{i}=1}^{\mathrm{n}}\left(\mathrm{Q}_{\mathrm{obs}}-\overline{\mathrm{Q}}_{\mathrm{obs}}\right)^{2}}\right]
$$

The OPI value is a criterion that indicates model performance. It is between $-\propto$ to 1 . If the higher OPI is closer to 1 , the model's performance is favorable [34].

Where; $\mathbf{Q}_{\mathbf{o b s}}$ is the amount of runoff obtained from the measurement, $\mathbf{Q}_{\mathbf{c a l}}$ is the amount of runoff obtained from the calculation, $\overline{\mathbf{Q}}_{\mathbf{o b s}}$ is the average runoff from the measure, $\overline{\mathbf{Q}}_{\mathbf{c a l}}$ is the average runoff from the calculation, $\mathbf{Q}_{\mathbf{o b s} \text {,max }}$ is the runoff from the highest measurement, $\mathbf{Q}_{\mathbf{o b s} \text {,min }}$ is the runoff from the lowest measurements, and $\mathbf{n}$ is the amount of information.

\section{Results and Discussion}

\subsection{The results of calibrating and verifying the GR2M Model}

Table 2 shows the results of the model's calibration and verification. It explicitly indicated that the GR2M model could be applied for modeling monthly rainfall-runoff in the southern region of Thailand. The average performance criteria gave NSE, $r$, and OPI values for the calibration stage of $0.637,0.825$, and 0.757 , respectively, and those values for the verification stage of $0.465,0.750$, and 0.639 , respectively. Lian, et al. [35]suggested that the model had a satisfactory prediction since NSE was in the range of 0.36 to 0.75 . By obtaining an r-value of more than 0.70 , it indicated a strong positive linear relationship between simulated and observed runoff [36]. Moreover, the OPI value of more than 0.60, showed the model had relatively high forecasting accuracy. The three performance criteria previously mentioned emphasized a strong consistency between the runoff data obtained from the measurements and model-simulated for our study.

Considering the best top-three model performance stations obtaining from X.64, X.70, and X.209, NSE, r, and OPI values for both calibration and verification processes gave more than 0.76 , it showed the GR2M model performed quite satisfactorily for simulating monthly runoff. Conversely, the worst top-three model performance stations were X.212, X.186, and X.192. They gave NSE, r, and OPI values for both calibration and verification processes less than 0.690. However, some runoff stations, i.e., X.205, X.229, and X.237, had a negative NSE value. It represented overfitting models for those three runoff stations and could not be generally applied. Although many attempts had been being made for the model's calibration and verification processes, the quality and accuracy of measured hydrological and meteorological data is the most important thing to concern and check the consistency.

Figure 4 illustrates the relationship between rainfall and runoff obtained from running the GR2M model. We herein present six examples of runoff stations, i.e., X.64, X.70, X.209, X.212, X186, and X.192. The best top-three and the worst top-three model performance stations are presented. Likewise, the bar chart in blue represents rainfall time-series variation. The line graphs in orange and green also show the observed and simulated runoff time-series variation, respectively. For both runoff time-series variation, the solid and dot lines mean calibration and validation periods, respectively. The small difference runoff time-series value was observed for the best top-three model performance stations. The immense difference runoff time-series value was observed for the worst top-three model performance stations. However, both cases underestimated runoff 
value; that is, the simulated runoff was lower than the observed runoff. It could realize when using the calibrated and verified GR2M model, especially for water resources management and planning for rainy and dry seasons.

Table 2. Results of calibrating and verifying the GR2M model

\begin{tabular}{|c|c|c|c|c|c|c|c|c|c|c|c|c|c|c|c|}
\hline \multirow{3}{*}{ No. } & \multirow{3}{*}{ Code } & \multicolumn{6}{|c|}{ Performance Criteria } & \multirow{3}{*}{ No. } & \multirow{3}{*}{ Code } & \multicolumn{6}{|c|}{ Performance Criteria } \\
\hline & & \multicolumn{3}{|c|}{ Calibration } & \multicolumn{3}{|c|}{ Validation } & & & \multicolumn{3}{|c|}{ Calibration } & \multicolumn{3}{|c|}{ Validation } \\
\hline & & NSE & $\mathbf{r}$ & OPI & NSE & $\mathbf{r}$ & OPI & & & NSE & $\mathbf{r}$ & OPI & NSE & $\mathbf{r}$ & OPI \\
\hline 1 & X.44 & 0.942 & 0.973 & 0.949 & 0.465 & 0.705 & 0.657 & 20 & & 0.563 & 0.756 & 0.668 & 0.349 & 0.654 & 0.548 \\
\hline 2 & X.67A & 0.978 & 0.99 & 0.974 & 0.719 & 0.852 & 0.795 & 21 & X.191 & 0.177 & 0.492 & 0.505 & 0.664 & 0.831 & 0.749 \\
\hline 3 & X.71B & 0.688 & 0.954 & 0.793 & 0.605 & 0.797 & 0.733 & 22 & $X .192 b$ & 0.165 & 0.462 & 0.493 & 0.167 & 0.670 & 0.451 \\
\hline 4 & X.90 & 0.772 & 0.887 & 0.85 & 0.468 & 0.502 & 0.478 & 23 & X.196 & 0.333 & 0.691 & 0.544 & 0.283 & 0.691 & 0.505 \\
\hline 5 & X.109 & 0.925 & 0.987 & 0.94 & 0.577 & 0.849 & 0.696 & 24 & $X .205^{c}$ & 0.518 & 0.755 & 0.693 & -0.119 & 0.663 & 0.289 \\
\hline 6 & X.113 & 0.736 & 0.91 & 0.821 & 0.479 & 0.796 & 0.648 & 25 & Х.207 & 0.758 & 0.878 & 0.798 & 0.836 & 0.920 & 0.856 \\
\hline 7 & X.170 & 0.805 & 0.903 & 0.867 & 0.038 & & 0.392 & 26 & & 0.796 & 0.906 & 0.838 & 0.751 & 0.894 & 0.808 \\
\hline 8 & X.174 & 0.725 & 0.975 & 0.821 & 0.385 & 0.731 & 0.61 & 27 & $X .209^{a}$ & 0.880 & 0.943 & 0.896 & 0.870 & 0.935 & 0.883 \\
\hline 9 & X.240 & 0.975 & 0.993 & 0.973 & 0.511 & 0.735 & 0.687 & 28 & X.245 & 0.476 & 0.715 & 0.636 & 0.199 & 0.503 & 0.457 \\
\hline 10 & X.53A & 0.822 & 0.908 & 0.868 & 0.714 & 0.847 & 0.793 & 29 & X.56 & 0.813 & 0.911 & 0.868 & 0.676 & 0.866 & 0.746 \\
\hline 11 & & 0.787 & 0.888 & 0.838 & 0.941 & 0.970 & 0.942 & 30 & & 0.833 & 0.915 & 0.871 & 0.226 & 0.623 & 0.461 \\
\hline 12 & X.158 & 0.573 & 0.759 & 0.714 & 0.752 & 0.869 & 0.818 & 31 & $X .228$ & 0.111 & 0.527 & 0.450 & 0.346 & 0.702 & 0.554 \\
\hline 13 & $X .212^{b}$ & 0.383 & 0.668 & 0.594 & 0.173 & 0.431 & 0.467 & 32 & $X .229^{c}$ & 0.564 & 0.794 & 0.730 & -0.437 & 0.407 & 0.120 \\
\hline 14 & X.55 & 0.654 & 0.903 & 0.761 & 0.987 & 0.996 & 0.980 & 33 & $X .234$ & 0.854 & 0.934 & 0.890 & 0.713 & 0.882 & 0.773 \\
\hline 15 & $X .70^{a}$ & 0.780 & 0.943 & 0.845 & 0.923 & 0.976 & 0.916 & 34 & X.235 & 0.430 & 0.758 & 0.648 & 0.404 & 0.679 & 0.596 \\
\hline 16 & & 0.557 & 0.912 & 0.702 & 0.957 & 0.986 & 0.950 & 35 & & 0.801 & 0.896 & 0.857 & 0.513 & 0.719 & 0.647 \\
\hline 17 & X.167 & 0.892 & 0.973 & 0.912 & 0.278 & 0.803 & 0.534 & 36 & $X .237^{c}$ & 0.734 & 0.277 & 0.411 & -0.305 & 0.497 & 0.202 \\
\hline 18 & X.203 & 0.732 & 0.970 & 0.809 & 0.897 & 0.973 & 0.904 & 37 & X.239 & 0.376 & 0.754 & 0.602 & 0.055 & 0.673 & 0.388 \\
\hline \multirow[t]{5}{*}{19} & $X .186^{b}$ & 0.400 & 0.660 & 0.580 & 0.405 & 0.680 & 0.620 & & & & & & & & \\
\hline & & & & & & & & \multicolumn{2}{|c|}{ Maximum } & 0.978 & 0.993 & 0.974 & 0.987 & 0.996 & 0.987 \\
\hline & & & & & & & & \multicolumn{2}{|c|}{ Minimum } & 0.730 & 0.277 & 0.411 & -0.437 & 0.407 & -0.437 \\
\hline & & & & & & & & \multicolumn{2}{|c|}{ Average } & 0.637 & 0.825 & 0.757 & 0.005 & 0.750 & 0.005 \\
\hline & & & & & & & \multicolumn{3}{|c|}{ Standard Deviation } & 0.256 & 0.170 & 0.153 & 0.354 & 0.166 & 0.354 \\
\hline
\end{tabular}

Remark: TSS =Thale Sap Songkhla; PWC =Peninsular-West Coast; PEC =Peninsular-East Coast.

${ }^{a}$ the green bold italic text shows the best top-three model performance stations

${ }^{b}$ the red bold italic text shows the worst top-three model performance stations

c the blue bold italic text shows the worst top-three model performance stations 

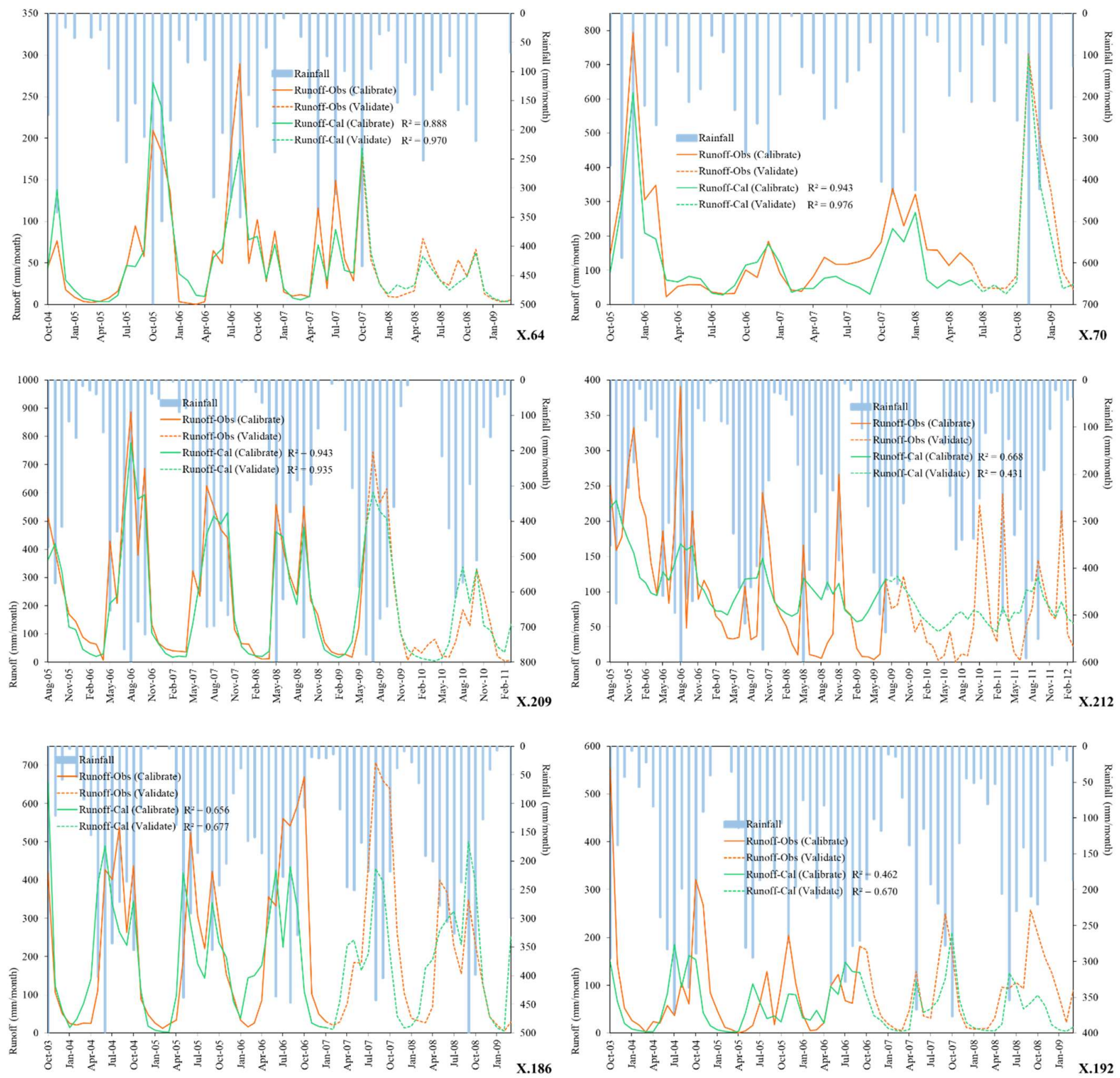

Figure 4. The relationship between rainfall and runoff of models (GR2M) stations.

\subsection{The optimal values of production store capacity (X1) and groundwater exchange rate (X2)}

Figure 5 shows suitable $X 1$ and $X 2$ parameters of the GR2M model for each runoff station obtained from the model's calibration and verification. The production store capacity ( $\mathrm{X} 1$ ) value results ranged from $2.00 \mathrm{~mm}$ to $10.00 \mathrm{~mm}$. It showed a spatial variation of $X 1$ value, and its values ranged from the minimum $2.00 \mathrm{~mm}$ ) and maximum (10.00 mm) values. The average and standard deviation values of $\mathrm{X} 1$ were $5.71 \mathrm{~mm}$, and $2.49 \mathrm{~mm}$, respectively. Furthermore, the skewness and kurtosis values of X1 were -0.52 and -1.03 , respectively. It could physically explain river basin characteristics in terms of production store capacity (X1) that it had left skew, platykurtic, and non-symmetric distributions. The groundwater exchange rate (X2) value results ranged from 0.54 to 1.00 . Those X2 values mostly reached the maximum value (1.00). The average and standard deviation values of X2 were 0.93 and 0.12 , respectively. Moreover, the skewness and kurtosis values of X2 were -2.01 and 3.69, respectively. It could physically explain river 
basin characteristics in terms of the groundwater exchange rate (X2) that it had left skew, leptokurtic, and non-symmetric distributions. The positive value of groundwater exchange rate (X2) displayed no groundwater flows outside the basin.

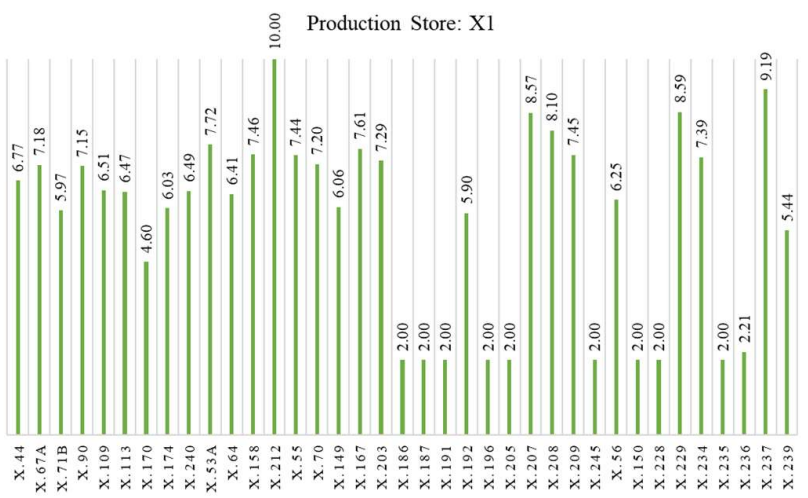

(a)

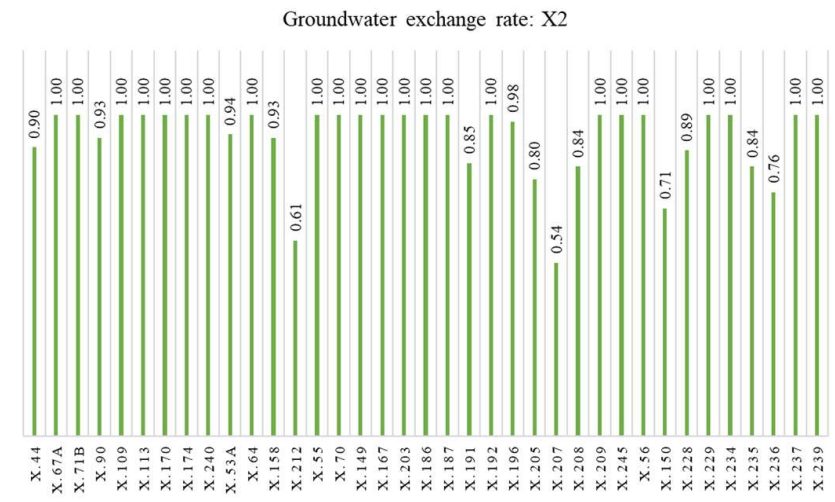

(b)

Figure 5. The suitable $X 1$ and $X 2$ parameters of the GR2M model: (a) Production Store: $X 1$, and (b) Groundwater exchange rate: $X 2$

\subsection{The spatial distribution of X1 and X2 values using Inverse distance weighting (IDW) method}

Figure 6 shows the spatial distribution of X1 and X2 values using the IDW method. As seen from Figure 5 (a), the low production store capacity (X1) value yellow and green color) was generally located on the Peninsular-West Coast. The major area roughly was covered by the average production store capacity (X1) value $(5.71 \mathrm{~mm})$, as shown that most areas were a light blue color. Only the northern part of Surat Thani province shows the high production store capacity (X1) value, which shows the dark blue zone. For the groundwater exchange rate (X2) as depicted in Figure 5 (b), most areas were governed by the dark blue zone. It indicated that most areas in the southern basin, Thailand, had a high groundwater exchange rate (X2). Furthermore, it agreed to the average X2 value of 0.93. The northern part of Surat Thani province and some areas of Chumporn, Trang, and Satun provinces show the low groundwater exchange rate (X2) value, as portrayed in the yellow and green zone. In the case that we do not have a measured gauged or ungauged, we can use these figures to roughly determine the values of $X 1$ and $X 2$, and then if we know areal rainfall and evaporation, we also can estimate the runoff via the GR2M model. 


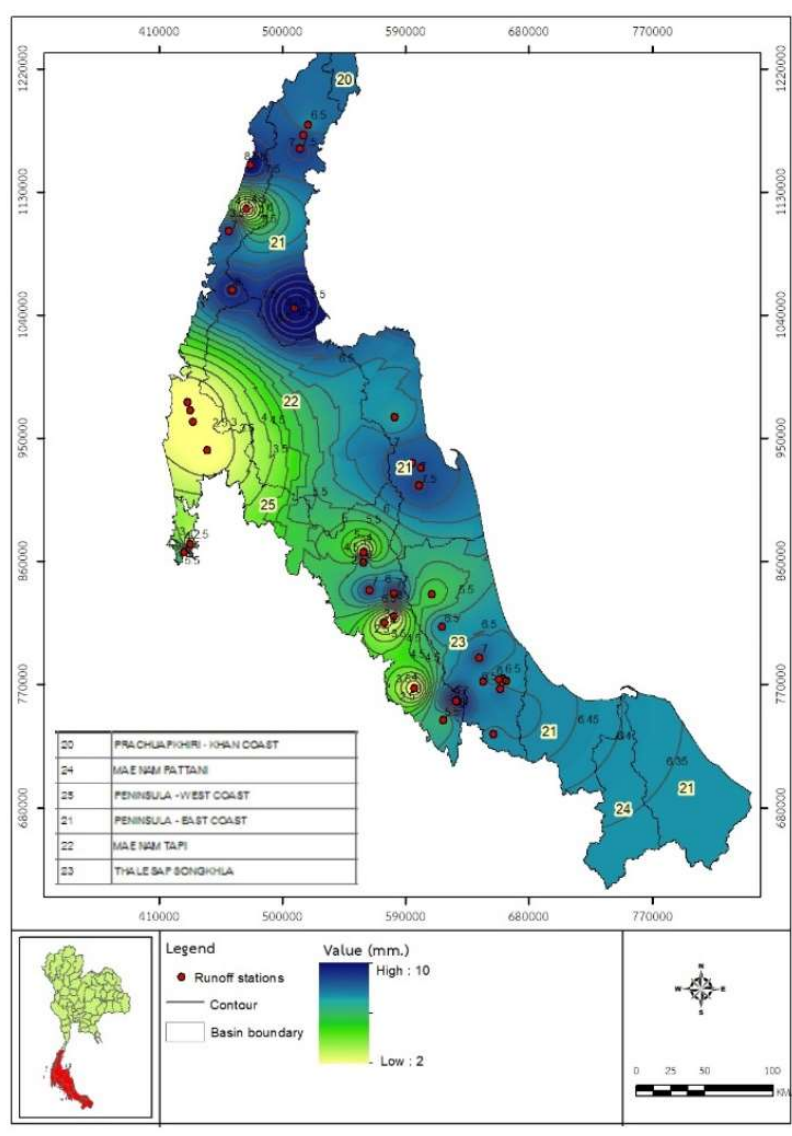

(a)

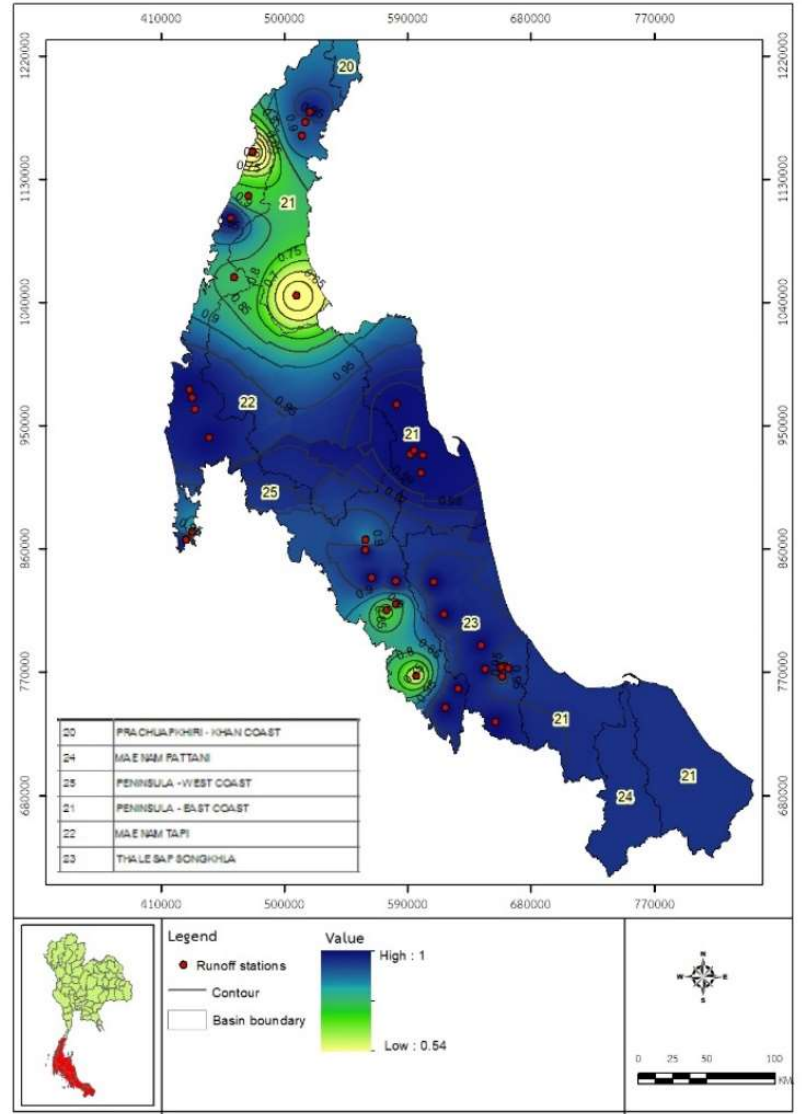

(b)

Figure 6. The spatial distribution of $\mathrm{X} 1$ and $\mathrm{X} 2$ values using IDW method: (a) Production Store: $\mathrm{X} 1$, and (b) Groundwater exchange rate: $\mathrm{X} 2$

\section{Sensitivity Analysis}

The sensitivity analysis [10] was experimented on in our research work to understand the effects of the model's two parameters: $X 1$ and $X 2$. We randomly selected three runoff stations (X.44, X.64, and X.240) as the representative for all 37 runoff stations due to the experiment's sensitivity. By fixing the optimal $X 2$ value obtained from calibration and verification stages and then varying the $X 1$ value in its range from the minimum to maximum ( $2 \mathrm{~mm}$. to $10 \mathrm{~mm}$.) [30,31], we received the results of X1's sensitivity analysis. Similarly, by fixing the optimal $\mathrm{X} 1$ value obtained from calibration and verification stages and then varying the $X 1$ value in its range from the minimum to maximum ( -1 to 1) $[30,31]$, we got the results of $X 2$ 's sensitivity analysis. It was rarely reported about the sensitivity analysis for the GR2M model's two parameters to our best knowledge. It was the early attempt to conduct their sensitivity analysis. As evidentially presented in Figure 7 , The $\mathrm{X} 1$ value was susceptible. Apart from the optimal value obtained from the calibration and verification stages, the other value gave a lower model's performance. Considering the $\mathrm{X} 2$ value, we found that the higher value (approximately more than 0.90) was trial, it gave the higher model's performance. It also confirmed and corresponded with the results, as found in Figures 5 and 6. 

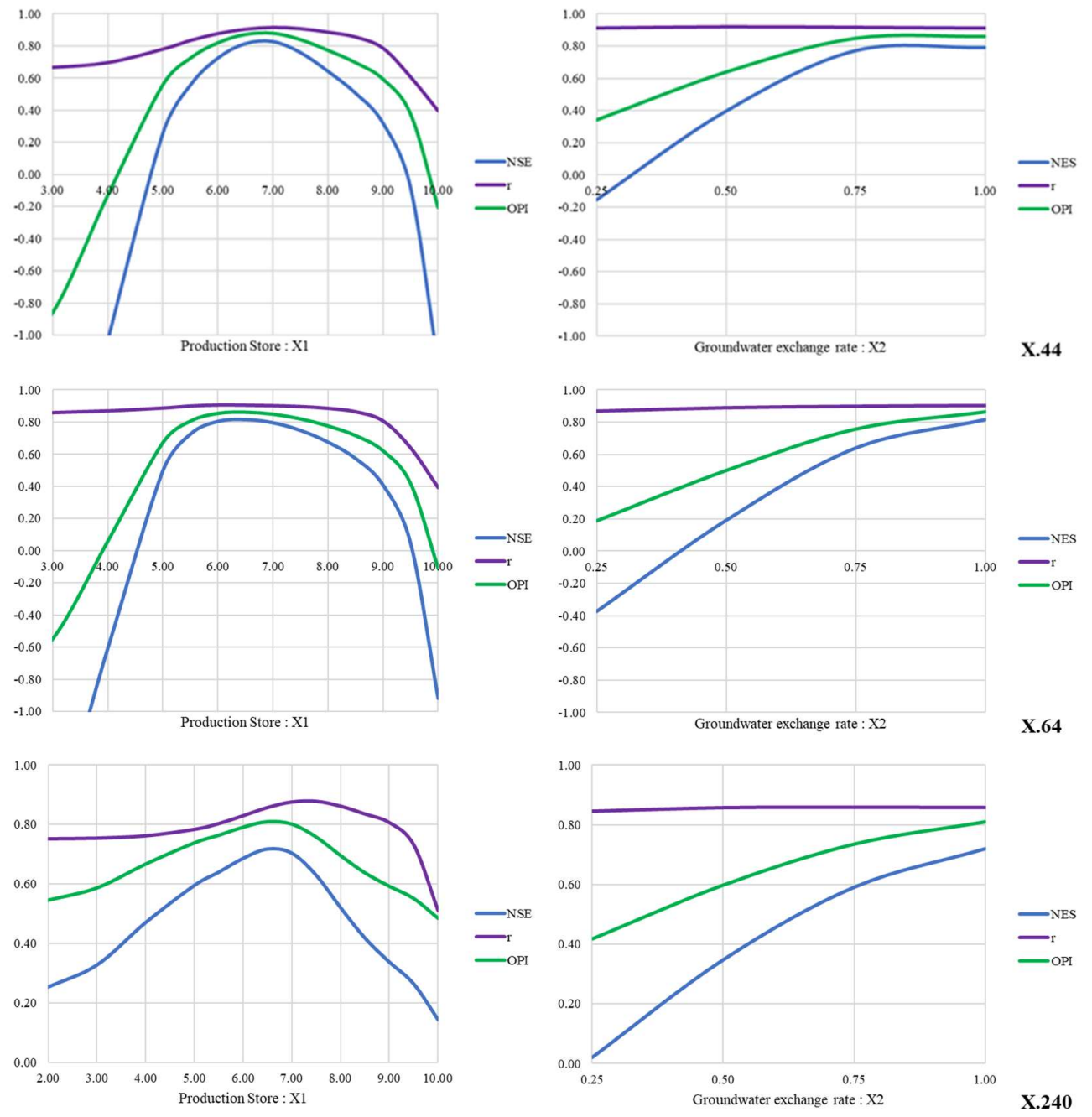

Figure 7. The sensitivity analysis of the GR2M model's two parameters: X1 and X2.

\section{Conclusion}

With only two parameters, namely, the production store (X1) and the exchange coefficient water (X2), our research work explicitly indicated GR2M model could be applied for modeling monthly rainfall-runoff in the southern region of Thailand. The model's calibration results for 37 runoff stations gave the average of Nash, r, and OI of 63.74, 0.825 , and 0.757 , and those values for verification of $46.46,0.750$, and 0.639 , respectively. The range of $\mathrm{X} 1$ was between 2.00 and 10.00 and the range of $\mathrm{X} 2$ was between 0.54 and 1.00. It was susceptible to the $\mathrm{X} 1$ value. The other value is given lower model efficiency, apart from the optimum value obtained from the calibration and verification phases. We also found that the higher value of X2 (approximately more than 0.90 ) gave the higher model's performance. Personnel concerning water resources planning and management can apply our work for a guideline for utilizing the GR2M model to determine monthly runoff in other runoff stations located in the southern region, Thailand. It is because there are similar hydrological, geological, and topological basin characteristics. For more GR2M model's reliability, a more extended period of recorded hydrological data is required and more runoff station installation to cover the variety of existing watershed characteristics. 
Vaze, J.; Chiew, F.; Perraud, J.M.; Viney, N.; Post, D.; Teng, J.; Wang, B.; Lerat, J.; Goswami, M. Rainfall-runoff modelling across southeast Australia: datasets, models and results. Australasian Journal of Water Resources 2011, 14, 101-116.

.
Peña-Arancibia, J.L.; Stewart, J.P.; Kirby, J.M. Water balance trends in irrigated canal commands and its implications for sustainable water management in Pakistan: Evidence from 1981 to 2012. Agricultural Water Management 2020, 106648.

.

López-Lambraño, A.A.; Martínez-Acosta, L.; Gámez-Balmaceda, E.; Medrano-Barboza, J.P.; Remolina López, J.F.; López-Ramos, A. Supply and demand analysis of water resources. Case study: Irrigation water demand in a semi-arid zone in Mexico. Agriculture 2020, 10, 333.

Zhang, X.; Guo, P.; Zhang, F.; Liu, X.; Yue, Q.; Wang, Y. Optimal irrigation water allocation in Hetao Irrigation District considering decision makers' preference under uncertainties. Agricultural Water Management 2021, 246, 106670.

Nounangnonhou, T; FIFATIN, F.; Lokonon, B.; Acakpovi, A.; Sanya, E. Modelling and Prediction of Ouémé (Bénin) River Flows by 2040 Based on GR2M Approach. LARHYSS Journal P-ISSN -1112-3680/E-ISSN -2602-7828, 2018, 71-91.

Chen, Q.; Chen, H.; Wang, J.; Zhao, Y.; Chen, J.; Xu, C. Impacts of climate change and land-use change on hydrological extremes in the Jinsha River Basin. Water 2019, 11, 1398.

Kabiri, R.; Bai, V.R.; Chan, A. Assessment of hydrologic impacts of climate change on the runoff trend in Klang Watershed, Malaysia. Environmental Earth Sciences 2015, 73, 27-37.

Lin, B.; Chen, X.; Yao, H.; Chen, Y.; Liu, M.; Gao, L.; James, A. Analyses of landuse change impacts on catchment runoff using different time indicators based on SWAT model. Ecological Indicators 2015, 58, 55-63.

Kwak, J.; Lee, J.; Jung, J.; Kim, H.S. Case Study: Reconstruction of Runoff Series of Hydrological Stations in the Nakdong River, Korea. Water 2020, 12, 3461.

Ballinas-González, H.A.; Alcocer-Yamanaka, V.H.; Canto-Rios, J.J.; Simuta-Champo, R. Sensitivity Analysis of the RainfallRunoff Modeling Parameters in Data-Scarce Urban Catchment. Hydrology 2020, 7, 73.

Lerat, J.; Thyer, M.; McInerney, D.; Kavetski, D.; Woldemeskel, F.; Pickett-Heaps, C.; Shin, D.; Feikema, P. A robust approach for calibrating a daily rainfall-runoff model to monthly streamflow data. Journal of Hydrology 2020, 591, 125129.

Abdessamed, D.; Abderrazak, B. Coupling HEC-RAS and HEC-HMS in rainfall-runoff modeling and evaluating floodplain inundation maps in arid environments: case study of Ain Sefra city, Ksour Mountain. SW of Algeria. Environmental Earth Sciences 2019, 78, 1-17.

Zhang, C.; Wang, R.b.; Meng, Q.-x. Calibration of conceptual rainfall-runoff models using global optimization. Advances in Meteorology 2015, 2015.

Khazaei, M.R.; Zahabiyoun, B.; Saghafian, B.; Ahmadi, S. Development of an automatic calibration tool using genetic algorithm for the ARNO conceptual rainfall-runoff model. Arabian Journal for Science Engineering 2014, 39, 2535-2549.

Dezetter, A.; Girard, S.; Paturel, J.-E.; Mahé, G.; Ardoin-Bardin, S.; Servat, E. Simulation of runoff in West Africa: Is there a single data-model combination that produces the best simulation results? Journal of Hydrology 2008, 354, $203-212$.

Okkan, U.; Fistikoglu, O. Evaluating climate change effects on runoff by statistical downscaling and hydrological model GR2M. Theoretical applied climatology 2014, 117, 343-361.

Lyon, S.W.; King, K.; Polpanich, O.-u.; Lacombe, G. Assessing hydrologic changes across the Lower Mekong Basin. Journal of Hydrology: Regional Studies 2017, 12, 303-314.

Zamoum, S.; Souag-Gamane, D. Monthly streamflow estimation in ungauged catchments of northern Algeria using regionalization of conceptual model parameters. Arabian Journal of Geosciences 2019, 12, 1-14.

Boulariah, O.; Longobardi, A.; Meddi, M. Statistical Comparison of nonlinear rainfall-runoff models for simulation in Africa North-West semi-arid areas. In Proceedings of 15th International conference on Environment Science and Technology, CEST2017 (00694); pp. 1-4.

Topalović, Ž.; Todorović, A.; Plavšić, J. Evaluating the transferability of monthly water balance models under changing climate conditions. Hydrological Sciences Journal 2020, 65, 928-950. 
Hadour, A.; Mahé, G.; Meddi, M. Watershed based hydrological evolution under climate change effect: An example from North Western Algeria. Journal of Hydrology: Regional Studies 2020, 28, 100671.

Rintis, H.; Setyoasri, Y.P. Rainfall-Discharge Simulation in Bah Bolon Catchment Area by Mock Method, NRECA Method, and GR2M Method. In Proceedings of Applied Mechanics and Materials; pp. 24-29.

O'Connor, P.; Murphy, C.; Matthews, T.; Wilby, R.L. Reconstructed monthly river flows for Irish catchments 1766-2016. Geoscience Data Journal 2020.

Thornthwaite, C.W. An approach toward a rational classification of climate. Geographical review 1948, 38, 55-94.

Kabouya, M. Modélisation pluie-débit aux pas de temps mensuel et annuel en Algérie septentrionale. Doctorat Sciences, Université Paris Sud Orsay, 1990.

Makhlouf, Z:; Michel, C. A two-parameter monthly water balance model for French watersheds. Journal of Hydrology 1994, $162,299-318$.

Mouelhi, S. Vers une chaîne cohérente de modèles pluie-débit conceptuels globaux aux pas de temps pluriannuel, annuel, mensuel et journalier. Doctorat Géosciences et ressources naturelles, ENGREF Paris, 2003.

Mouelhi, S.; Michel, C.; Perrin, C.; Andréassian, V. Stepwise development of a two-parameter monthly water balance model. Journal of Hydrology 2006, 318, 200-214.

Fathi, M.M.; Awadallah, A.G.; Abdelbaki, A.M.; Haggag, M. A new Budyko framework extension using time series SARIMAX model. Journal of hydrology 2019, 570, 827-838.

Bachir, S.; Nouar, B.; Hicham, C.; Azzedine, H.; Larbi, D. Application of GR2M for Rainfall-Runoff Modeling in Kébir Rhumel Watershed, North East of Algeria. World Applied Sciences Journal 2015, 33, 1623-1630.

Rwasoka, D; Madamombe, C.; Gumindoga, W:; Kabobah, A. Calibration, validation, parameter indentifiability and uncertainty analysis of a 2-parameter parsimonious monthly rainfall-runoff model in two catchments in Zimbabwe. Physics Chemistry of the Earth, Parts A/B/C 2014, 67, 36-46.

Zolfaghari, M.; Mahdavi, M.; Rezaei, A.; Salajegheh, A. Evaluating GR2M model in some small watersheds of Iran (Case study Gilan and Mazandaran Provinces). Journal of Basic Applied Scientific Research 2013, 3, 463-472. Kimmany, B. EFFECTIVENESS OF HYDROLOGIC MODELS FOR STREAMFLOW PREDICTION IN THE NAM SONG RIVER BASIN. Chulalongkorn University, 2016.

Sarzaeim, P.; Bozorg-Haddad, O.; Bozorgi, A.; Loáiciga, H.A. Runoff projection under climate change conditions with data-mining methods. Journal of Irrigation Drainage Engineering 2017, 143, 04017026.

Lian, Y.; Chan, I.-C.; Singh, J.; Demissie, M.; Knapp, V.; Xie, H. Coupling of hydrologic and hydraulic models for the Illinois River Basin. Journal of hydrology 2007, 344, 210-222. analysis for marketing 2009, 17, 139-142. 